\title{
SPECIFICS OF SIBERIAN IDENTITY IN THE CONTEXT OF FORMATION OF THE ARTISTIC CONCEPT "SIBERIA" IN THE WORKS OF KRASNOYARSK ARTIST ANTON DOVNAR
}

\author{
M. Kolesnik, N. Libakova, V. Luzan, N. Sergeeva, E. Sertakova
}

\section{ABSTRACT}

This article is devoted to the study of the concept "Siberia" and its specifics of visualization in paintings on the example of the contemporary Krasnoyarsk artist Anton Dovnar. Of particular interest is the fact that the authors propose to consider the concept of "Siberia" not on the verbal, but rather on the visual level. The relevance of the study is in determining the additional possibilities of forming a regional identity, in expanding the characteristics and content of the concept "Siberia" owing to the variety and depth of the painterly artistic image. The article presents the results of analysis of such concepts as "a Siberian", "Siberian mentality", as well as formation of the concept "Siberia" in the artistic milieu of the city of Krasnoyarsk. The practical part of the article presents the results of the study of the art of the painter, his works in the genre of still life, which is defined as a genre of visual art that can figuratively reflect important aspects of life, tastes, habits, social position of people through the material nature of specific objects.

The findings show the specifics of visualization of the concept "Siberia" in the works of Anton Dovnar at all levels of expressiveness, available to painting: colour scheme, composition and subject matter. The study used general scientific methods of research, as well as the descriptive-discursive, analytical, generalizing-synthetic methods of art criticism.

\section{KEYWORDS}

Concept Siberia, visualization of the concept Siberia, Anton Dovnar, Siberian identity, modern Siberian art.

\section{INTRODUCTION}

In modern humanitarian studies conducted by Russian scholars, construction of the image of Siberia, Siberian identity, studying different aspects of concept "Siberia" from historical, linguistic and culturological perspectives take an important part. Researchers conduct detailed research of the issues of historiography and source study, the history of the population and settlements, business, labor history, management history, social and political processes and cultural development of Siberia in the historical past. They characterize economic, social, political, cultural and spiritual development of the region. For example, the culturological study of the phenomenon of "Siberia" includes such topics as childhood culture [1], the specifics of regional identity and characteristics of ethnic and cultural identity of the indigenous small-numbered peoples of the North of Siberia [2], the problem of ethnic migration on the territory of Siberia [3], possibilities of visual anthropology in the study of the indigenous peoples, living in the region [4]. Of great interest are the lingua-culturological studies, defining the features of space of the Siberian region [5], the specifics of the concept "Siberia" in the minds of representatives of other cultures [6], features of understanding the space of this region as mythological one [7]. Some studies of the identity of the Siberian region are carried out by art experts $[8,9,10]$. Most of the works are of sociological experimental research type, dedicated to the defining the specifics of identity in the definitions of such concepts as "a Siberian", "Siberian taste", "Siberian smell" and others [11].

The aim of the research, presented in the article was to reveal the specifics of visualization of the concept "Siberia" in painting on the example art work of the Siberian painter Anton A. Dovnar. 
There are a lot of works dedicated to the creative work of the artist, written by Krasnoyarsk art experts, which contain the detailed analysis of the creative method of the artist, genre and narrative features of his works, and supply biographical information about the artist $[12,13,14] /$

In the present study, for the first time the concept "Siberia" is regarded not as a certain meaningful linguistic reality, but as a kind of visual-artistic imagery. Research objectives are to identify additional possibilities of forming regional identity, to expanding the scope of characteristics of such important concept as "Siberia" on the basis of variety and depth of the artistic painterly image. In this context, it seems relevant to study the works of the leading Siberian artist Anton A. Dovnar in the aspect of culturological and philosophical definitions, which should promote the deeper understanding of the meaningful aspects of his art.

\section{MATERIALS AND METHODS}

The study used the descriptive-discursive, analytical, generalizing, and synthetic methods of art criticism, as well as the general scientific empirical and theoretical methods, which were found suitable for a particular status of the artistic image of the artwork, which we considered promising for further analysis. Besides that, the conceptual propositions of the modern theory of the fine arts, as well as the method of philosophical -artistic analysis and main propositions of the theory of visual thinking were also applied.

In the practical part of the research the following works of Anton A. Dovnar were analyzed by means of applying philosophical-artistic method: "Harness" (1975), "Grindstone" (1994), "Still life with scythes (litovki)" (1997), " Trap net (Venter)" (1998), "Window" (1999), "My fried Uchum" (1989), "Bathhouse" (1993), "'Garden berry" (2001), "Smoked char (golets)" (1991), "Siberian furs" (2000), "Khantaisk gifts" (1986), "Balyk" (1986), "Cranberry (Kalina krasnaya)" (1993). The article presents the analysis of just some of these works of visual arts.

The works of the painter are stored and exhibited in the museums of Krasnoyarsk region, state and private collections in Russia, the USA, Germany, Poland, Japan and other countries.

\section{RESULTS AND DISCUSSION}

In modern linguistic researches of the concept "Siberia" a quite controversial image can be found in the minds of respondents. For example, one study devoted to revealing the specifics of perception of the Siberian region by representatives of the English-speaking linguistic and cultural community [6] showed that in their minds "Siberia" is perceived as, on the one hand, the area with rich natural potential, and on another - as a territory with a severe climate, which is absolutely not suitable for living. The author of the research noted that Siberia is perceived by domestic and foreign investors as an unpromising and unattractive region. Studies have shown that the external image of Siberia, reconstructed as the result of the associative experiment, with participation of 200 respondents, is not attractive.

Another study, on the basis of associative experiment was conducted by the scholars of the Department of Culturology of Siberian Federal University [11]. The results of the analysis revealed that the meanings, associated with the word "Siberia", have similarities with the above mentioned results. For example, frequent associations characterizing weather conditions are the words "cold", "frost", "snow". The authors of the research noted that on the one hand they have a negative meaning, but on the other hand, they reveal the uniqueness and the originality of the territory of Siberia. The uniqueness of the territory is revealed in the mentioning of the flora and fauna by modern youths. Among frequent association are such words as "nature", "forest", "rivers", "lakes", "mountains", "bears", "wolves". Another aspect of the concept "Siberia" is revealed in the study of E. A. Fedorova and V. P. Slivinskiy [7], regatding it 
as a particular mythological space in linguistic consciousness of Russian people. The authors note that Siberia is associated with a specific mythological space. The road to Siberia in the peoples' mind is perceived as the road to a sacred world, or the world of Other, which is associated with some remote world, forbidden, causing negative associations.

The concept "Siberia" possesses such qualitative characteristics as "diversity". Researchers studying the specifics of formation of Siberia noted that as part of Russia, Siberia had two images: separateness and integrity. Thus, "Siberia has a special identity, where the specific features of events and objects reflect not only the features of the territories, but also the specifics of minds of people, inhabiting this territory.

The name Siberia was first given to the territory where this group of people lived, but later, starting from the XIX century, the name was extended to the entire territory beyond the Urals. The process of gradual development of the territory of Siberia formed a specific perception of themselves and the territory they inhabited, in the minds of people living in this area This is indicated by the studies of "Siberian identity" and, as the researchers point out, spontaneous formation of such concepts as "a Siberian", "Siberian character", "Siberian mentality", "Siberian taste", etc. On the other hand, in the process of historical formation of the concept "Siberia", it is worth pointing out the trend of change of the notion "Siberia from something dark, wild (indicated by the images "penal servitude, hard labour" ,existing in the minds of Russians), to the modern image of resource-rich "spare land". The image of Siberia as "spare land "is born. [11].

Today, the Siberian art can be described as essential, but still lacking complete assessment of art experts, an under-researched component of Russian cultural life.

The works of the modern generation of Siberian artists shape the image of fine arts of the Siberia of the XXI century. The works of young artists inspire hope that the traditions of Siberian fine arts, which were formed for a long time, will not be interrupted, that they will continue in the works of the talented artists.

At all stages of formation of the artistic environment in Siberia, the identity of Siberian artists was very important. The artists were proud of their Siberian origin, they actively used Siberian images in their landscapes, they depicted Siberian character in various compositions in the genre of portraiture. They also painted historical compositions, devoted to various aspects of the history of Siberia. It is important that artists also tried to visualize Siberian features in their still lifes: vegetation of Siberia in numerous floral still lifes (A. Gorenskiy, A. Znak), trophies of Siberian hunting (A. Gorenskiy, . V. Shepelevich). The most consistent and versatile artist is Anton A. Dovnar, the study of whose still life art was the subject of our research.

Anton A. Dovnar by virtue of both his biography and his creative heritage rightfully belongs to the constellation of the brightest Krasnoyarsk artists, who were born, grew up, were educated on the Siberian land and who depicted the unfearing Siberian beauty.

The palette of Anton A. Dovnar consists of silver and ochre tones, conveying the low-keyness of Siberian nature, the exotic brightness of colour, depending on the time of the year and the mood of the landscape.

The artist sought his inspiration in his travelling around the region, starting from the lower reaches of the Yenisei. After that, all his life Anton A. Dovnar made the long journey to the North, where he created the documentaryly accurate and artistically imageful ethnographic series, taking the important place in body of work of the artist. In these sketches he gave the detailed record of the following: the date of the sketch, the depicted place and the full name of the depicted object, striving to be absolutely accurate and detailed in its depicting. All these left a significant imprint on the artistic technique of the Siberian creator of still lifes. The realism of his depiction contributed to creating the image Siberian still lifes. 
One of the main genres in the art of Anton A. Dovnar was the genre of still life. Still lifes have their own value and are also an integral part of the composition of genre paintings or portraits. They clearly and beautifully represent the natural beauty of colors, the richness of nature, and recreate the image of the rich abundance of Siberia. Their characteristic feature is that the subjects are usually depicted in close up, so that the eye can feel them, as if assessing their material qualities- their weight, plasticity of shapes, their shape and surface texture, their details, as well as their interaction with the environment- their live in the environment.

The artist reveals the beauty of the familiar, everyday things, using them to talk about himself and his own world. He learnt about this beauty, by means of observing hand-made works of folk craftsmen. There is nothing which is excessive in these simple things. These objects are not just authentic; they are brought to life by life itself. His still lifes with berries, mushrooms, fishes, pumpkins are real hymn to the beauty of nature's forms and colours. He could find the exact colours and tones, to subtly convey the harmony of life.

Still lifes by Anton A. Dovnar often combine the landscape, interior or portrait. Krasnoyarsk art historian Marina V. Moskalyuk gives a detailed analysis of the works in the genre of still life in her book. The author highlights several key aspects of the still life, which to a greater or lesser extent, prevail in a specific work [13]:

1) Still lifes, which depict the tools of a man. Based on the analysis of such works of the artist, we can derive visual concepts, basing on which the image of Siberia and a Siberian is constructed;

2) Still lifes, which combine the genre of landscape or interior, revealing the theme of relationship between man and nature;

3) The world of natural abundance of Siberia is represented in still lifes with flowers, vegetables and berries;

4) Still lifes that reveal the spiritual world of Siberia.

Philosophical-artistic analysis of several paintings, belonging to the identified categories of the genre of still life, has produced the results, that have greatly enriched the content of the concept "Siberia", and have outlined the visual images of Siberian identity.

As representative of the artist's work in the genre of still life, we have selected his work, "My friend Uchum" (canvas, oil, 133x105, 1989).

The piece is executed in silver-gray colour scheme characteristic of the artist's palette, it is almost monochrome, very restrained and laconic in its color scheme. This still life is a picture of items typical for the Northern area: fishing tackle, wooden tub, oars. In the center of the composition there is a dog, whose figure alludes simultaneously at tranquil and alerted existence in the world. In the background there is a wooden house, which, coupled with the hanging gear is a kind of theatrical stage, but only in the sense that it demonstrates a small but important part of earthly existence. An interesting point is that the still life includes the depiction of a living being. Thus, the work visualizes the close and inextricable link between the man and the world of living nature, whose parts have personality and habits of their own.

The depicted elements of the exterior such as massive logs, going beyond the format of the picture, the heavy and large pair of oars, a wide fishing net with sinkers and floats, generate visual concepts of "power", "strength", "might", "labour".

The objects, presented in this still life, emphasize the immense importance of labour in human life, because with their help the man obtains his means of livelihood. They all refer to a traditional occupation as a defining way of existence of a man on the territory of Siberia.

Therefore, on the basis of the conducted analysis we can make the conclusion that the artist visualizes the image of a Siberian as a person, living in constant labour and standing firmly on the ground, owing to his ability to cooperate with his natural environment. Another work of the artist, chosen for the analysis, is "Mother's bread" 
(canvas, oil, 1980). It draws attention by the brightness of its colour scheme: bright and pure colours, which the painter uses in depicting the objects, and abundance of cool shades of blue and green, emphasizing the variety of colour.

The picture presents a small fragment of the dwelling, namely the windowsill, part of the window, besides that the picture also depicts the natural space outside the window. The window sill is covered with a light crocheted cloth, we can also see the edge of the crocheted curtain on the window. All these elements create festive and elegant atmosphere of the still life. Again, the considerable space of the work is devoted to the subject, made by human hands - a knitted cloth, whose details are carefully depicted.

The central elements of the still life are also three breads - Easter cakes, sitting on three plates. In the foreground on a separate small plate there are red eggs. Outside the window there are the branches of a blossoming willow, forming laced ornament, created by nature itself. The depicted objects are the attributes of celebration of the Orthodox Easter. Thus, the artist emphasizes the relationship with the spiritual tradition of the Russian people, with its rich culture and history.

The three-part structure of space division, indicated not only by the three Easter cakes, but also by the three sashes of the windows, and presence of special festive elements make the space of the window similar to the altar, with the gifts in the form of bread. These gifts are created by the hands of a mother- a woman, a human,- and at the same time by nature, which is the mother of all mankind. Thus, here is again emphasized such feature of the world outlook of a Siberian as the feeling of being in unity with nature, man is the son of nature.

In addition, the work "Mother's bread" visualizes the connection with the spiritual tradition of Russian culture, which is crucial for Siberian culture and life of a Siberian that cannot be conceived in isolation from it.

On the other hand, there is the abundance and the bright inner world of existence in a beautiful piece of "Kalina Krasnaya" (canvas, oil, 89x74, 1993). The artist combines the genres of portrait and still life, so that the main character of the artwork is a basket, filled with berries of snow ball tree, which is presented in the center of the canvas on the chair of a bright red color with flashes of gold leaves. They reveal such visual concepts as "full", "overfilled", "plentitude", "abundant", "generous", "well-off".

\section{CONCLUSION}

In the process of historical formation of the concept "Siberia" there was a noteworthy trend of changing the notion "Siberia" from something gloomy and wild (indicated by the image of "penal servitude, hard labour" in the minds of Russian) to the contemporary image of a recourse -rich "spare land".

Most researchers, studying the processes of historical development of Siberia, the formation of political, domestic, cultural traditions, note that the formation of the image of "Siberia" in the minds of people is directly affected by the territory itself, with its natural, geographical, and climatic conditions. Studying the image of "Siberia" through the prism of paintings, it should be noted that undoubtedly, the artistic image is always connected with real life by the author of the artwork himself. Creative work of the Siberian artist Anton A. Dovnar, preserving the features of the regional art, largely enriched the main national trends, expanded, and revealed through visual art the concept and idea of Siberia, bringing it to the national Russian scale.

Still lifes by Anton A. Dovnar reveal a world of natural abundance of Siberia. Siberia is not just a geographical location, but it is the Siberian space, forming a particular worldview of its people. Still lifes demonstrate the specifics of Siberian culture and lifestyle. Genre features of the still life allow the artist to freely experiment, search for a new figurative language; they have caused greater than in other genres desire to increase the share of visual, non-verbalizable images. Having studied the 
visualization of the image of Siberia in the still lifes of the Siberian artist, we noted the following features:

1. Restrained color combinations, defining the courage and the austerity of the visual image;

2. Composition solutions tend to be frontal, symmetrical. They are clear, specific, stable;

3. The subject matter of still lifes (tools, trophies of hunting and fishing, vegetation and interiors) is entirely based on the traditional Siberian way of life, captures the well-established human relationships, emphasizes the inner content of the composition as a whole;

4. Still lifes with berries, mushrooms, fish visualize such concepts as "abundance", "diversity", "wealth", "generosity";

5. Siberia is a place where people are able to feel a special unity with nature, manifesting such qualities as "strength", "power", "hard work";

6. Cultural characteristics of the Siberian region are determined by the specifics of human existence in the world of nature, at the same time, there is a close connection with the spiritual tradition of all Russian people.

\section{REFERENCES}

[1] Koptseva N.P., Kistova A.V., Pimenova N.N. The Culture of childhood of the indigenous peoples of the North, Siberia and the Far East (the field studies of Chulym ethnocultural group in Tyukhtet district, Krasnoyarsk Krai), Modern problems of science and education, №1, pp. 422, 2014.

[2] Pimenova N.N. The Ethnic situation in the Krasnoyarsk Krai: the role of the cultural heritage of indigenous peoples, Modern problems of science and education, №4, pp. 596, 2014.

[3] Koptseva N.P., Reznikova K.V. Refinement of the causes of ethnic migration North Selkups based on the historical memory of indigenous ethnic groups Turukhansk district of Krasnoyarsk Krai. Bylye Gody, Russia, Vol. 38/issue 4, pp 1028-1038, 2015.

[4] Ilbeykina M.I. Features of visual-anthropological studies of indigenous peoples, Modern problems of science and education, №4, pp. 594, 2014.

[5] Inyutina L.A. The concept of the 'Siberian space' in the texts that reflect the linguistic consciousness of the XVII-XVIII centuries, Interexpo Geo-Siberia, Vol.6, №2, pp. 71-75, 2015.

[6] Tersky M.V., Malenova E.D. The concept "Siberia" in the minds of the representatives of the American linguistic culture, Bulletin of the Tambov University. Series Philology and cultural studies, №3(3), pp. , 2015.

[7] Fedorova E. A., Slivinsky V. P. Siberia in lingvo-mythological continuum of Russia: the problem of reflection in the Russian linguistic consciousness, Bulletin of the Kemerovo state University of culture and arts, №22-2, pp. , 2013.

[8] Semenova A.A., Soshenko M.V. The Image of Siberia in Artist Aleskander Surikov's Works // Journal of Siberian Federal University. Humanities \& Social Sciences, Vol.4 (12) pp. 1743-1766, 2014.

[9] Lomanova T. M. Siberia in the chart of the Krasnoyarsk artist R.K. Ruigi, News of Altai state University, № 4, pp. 25-30, 2006.

[10] Karlova O.A., Koptseva N.P. New art critic on the banks of the Yenisei. Monograph. Krasnoyarsk, P. 388, 2015.

[11] Karlova O.A., Koptseva N.P. New future of Siberia: expectations, challenges, solutions. Monograph. Krasnoyarsk, P. 362, 2014.

[12] Milovanov A. The character of a true Siberian: (about Anton A. Dovnar), Revelation Life, №4, pp. 21-23, 2004. 
[13] Moskalyuk M.V. Siberian artist Anton Dovnar: an album-monograph, Krasnoyarsk, P. 120, 2013.

[14] Moskalyuk M.V. All that is in the heart. Krasnoyarsk artists yesterday, today, tomorrow, Krasnoyarsk, P. 288, 2010.

[15] Zhukovskiy V. I., Koptseva N.P. Proposition of the theory of art. Krasnoyarsk, 2004. P. 257, 2004. 